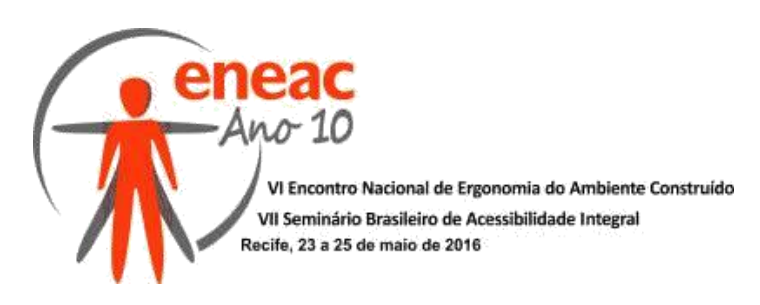

\title{
UTILIZAÇÃO DOS PARÂMETROS DE ACESSIBILIDADE EM EDIFÍCIOS PÚBLICOS: ESTUDO DE CASO - BIBLIOTECA PÚBLICA GOVERNADOR MENEZES PIMENTEL EM FORTALEZA
}

\author{
MARTINS, Liana Cândido (1); \\ NOGUEIRA, Carolyne de Castro Barros (2); \\ SOARES, Manuel Lima (3) \\ (1) Universidade Federal do Ceará, Graduanda em Arquitetura e Urbanismo \\ e-mail: lianalcm@gmail.com \\ (2) Universidade Federal do Ceará, Graduanda em Arquitetura e Urbanismo \\ e-mail: carolynedecastro@gmail.com \\ (3) Universidade Federal do Ceará, Graduando em Arquitetura e \\ Urbanismo e-mail: manuel.lima.s@hotmail.com
}

\begin{abstract}
RESUMO
O artigo analisa as condições de acessibilidade da Biblioteca Pública Governador Menezes Pimentel, em Fortaleza, fazendo uso dos parâmetros de acessibilidade espacial em reformas de edifícios públicos, através do Roteiro Básico para Avaliação de Acessibilidade nas Edificações, do Ministério Público, e de observação para coleta de dados. Conclui que, apesar de ter passado por reforma, a Biblioteca ainda apresenta necessidade de adequações para atender às diretrizes da Associação Brasileira de Normas Técnicas (ABNT), possibilitando o amplo acesso, de forma a não discriminar ou causar constrangimentos, nem proporcionar riscos aos seus usuários.
\end{abstract}

Palavras chave: Acessibilidade; Espaço Público; Biblioteca Pública.

\begin{abstract}
The article analyzes the conditions of accessibility of the Public Library Governador Menezes Pimentel in Fortaleza, making use of the spatial acessibility parameters in public buidings reforms, through the Basic Plan for Acessibility Evaluation in Buildings, of the Public Ministry, and observation to collect data. Concludes that, despite having undergone renovation, the library still presentes the need for adjustments in order to meet the guidelines of the Brazilian Association of Technical Standards (ABNT), enabling broad access, so as not to discriminate or embarass, or provide risk to its users.
\end{abstract}

Keywords: Acessibility; Public Space; Public Library.

\section{INTRODUÇÃO}

A acessibilidade é uma das questões principais na discussão da qualidade de vida da sociedade atual. A concepção de projetos arquitetônicos e urbanísticos deve seguir as normas técnicas de acessibilidade da ABNT, a fim de garantir a concretização dos princípios do desenho universal, assegurando iguais oportunidades para todos os usuários. 


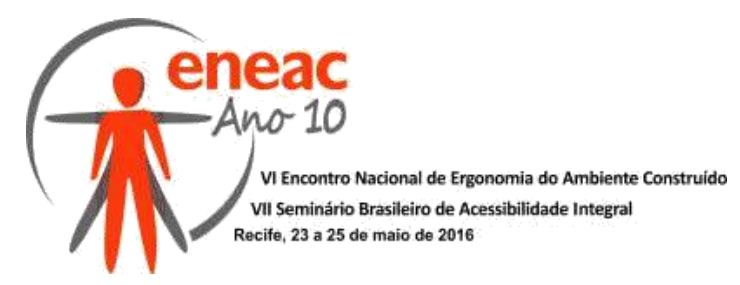

De acordo com o Censo de 2010 do Instituto Brasileiro de Geografia e Estatística - IBGE, cerca de 45,6 milhões de brasileiros se autodeclaram pessoa com deficiência, seja visual, auditiva, motora e mental ou intelectual, totalizando $23,9 \%$ da população brasileira. Observando essa realidade, podemos depreender a importância da promoção da acessibilidade em espaços públicos e edifícios, a fim de garantir o direito de ir e vir a todos os cidadãos, sendo este uma condição essencial para o pleno exercício de direitos de cidadania. Promover a acessibilidade é possibilitar inclusão social, é preservar a dignidade do indivíduo com deficiência, é reconhecê-lo como igual perante a sociedade no qual ele se insere, reduzindo barreiras que possam impedi-lo de vivenciar os espaços com segurança, comodidade e igualdade.

Tendo isto em vista, o Decreto 5.296/2004 estabelece que a construção, reforma ou ampliação de edificações de uso público ou coletivo, ou a mudança de destinação para estes tipos de edificação, deverão ser executadas de modo que sejam ou se tornem acessíveis à pessoa com deficiência ou com mobilidade reduzida.

O Governo Federal criou instrumentos como o Plano Nacional de Cultura (PNC) e o Plano Nacional dos Direitos da Pessoa com Deficiência - Plano Viver Sem Limite, de forma a auxiliar no processo de adaptação das edificações e dos espaços públicos, seja por meio de reformas físicas ou realização de atividades inclusivas, e na fiscalização das mesmas.

O PNC, instituído pela Lei 12.343, de 2 de Dezembro de 2010, tem por finalidade o planejamento e implementação de políticas públicas de longo prazo, até 2020 , voltadas à proteção e promoção da diversidade cultural brasileira. Neste plano, encontramos a Meta 29, que tem como objetivo atingir $100 \%$ de Bibliotecas Públicas, Museus, Cinemas, Teatros, Arquivos Públicos e Centro Culturais atendendo aos requisitos legais de acessibilidade e desenvolvendo ações de promoção da fruição cultural por parte das pessoas com deficiência, a fim de garantir que as pessoas com deficiência possam ter acesso aos espaços culturais, seus acervos e atividades.

Já o Plano Nacional dos Direitos da Pessoa com Deficiência - Plano Viver Sem Limite, lançado por meio do Decreto 7.612, de 17 de Novembro de 2011, pelo Governo Federal, visa implementar novas iniciativas e intensificar ações que, atualmente, já são desenvolvidas pelo Governo Federal em benefício da pessoa com deficiência.

De acordo com os planos governamentais citados, as instituições culturais, por terem o caráter de atendimento público, devem estar atentas ao cumprimento das leis existentes pertinentes a inclusão e acessibilidade. Desse modo, se torna obrigatório que os gestores das referidas instituições passem a tomar providências no sentido de, não só eliminar as barreiras de acesso físico das pessoas com deficiência ou mobilidade reduzida, mas também criar mecanismos de acesso e inclusão. O acesso aos espaços culturais, a seus acervos e atividades deve ser viabilizado de duas maneiras: por meio da adaptação ou adequação do espaço físico; como também de oferta de bens e de atividades culturais em formatos acessíveis.

Neste contexto, o presente artigo apresenta resultados obtidos em atividades de campo realizada na disciplina Desenho Universal do Curso de Arquitetura e Urbanismo da Universidade Federal do Ceará (UFC) em conjunto com o Grupo de Pesquisa sobre Condições de Acessibilidade em Edifícios Públicos do Departamento de Arquitetura e Urbanismo da UFC. O trabalho teve como objetivo abordar a questão da acessibilidade arquitetônica, de mobiliário e equipamentos em edifícios públicos, tendo como estudo de caso, a Biblioteca Pública Governador Menezes Pimentel pela sua importância histórica e como equipamento cultural da cidade de Fortaleza, no Estado do Ceará. 


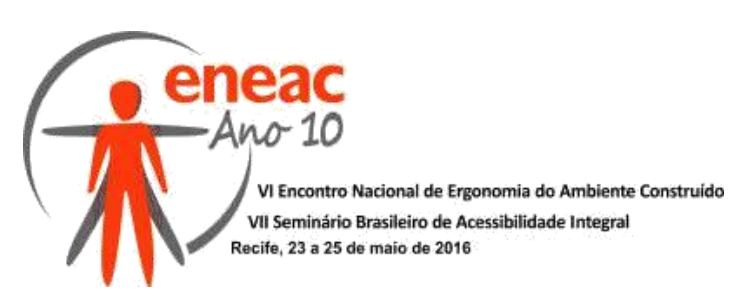

\section{METODOLOGIA}

O trabalho foi estruturado da seguinte forma: inicialmente pontuando os conceitos e princípios relacionados ao assunto, com base na revisão bibliográfica e leis pertinentes; seguindo pela análise do objeto de estudo em questão e seus resultados, e, por fim, apresentando as conclusões alcançadas por meio do desenvolvimento deste trabalho confrontando com as normas e legislação pertinente, buscando contribuir para o debate a cerca dos parâmetros de acessibilidade vigentes e do andamento das adequações nas edificações públicas.

Como metodologia de campo foram utilizadas visitas técnicas ao local para conhecimento e exploração dos espaços e serviços. A avaliação técnica foi baseada em vistorias, através da técnica de "walk-through"1 com observação direta e registros fotográficos, enfocando os aspectos técnico-funcionais e construtivos, referentes à acessibilidade de pessoas com deficiência. Segundo Selltiz et al (apud GIL, 2000, p.133) a observação é o uso dos sentidos para obter conhecimentos necessários para o quotidiano. É uma atividade do senso comum. Pode, no entanto, ser considerada como procedimento científico à medida que: serve a um objetivo formulado de pesquisas; é sistematicamente planejada; é sistematicamente registrada e ligada a proposições mais gerais e, é submetida à verificação e controles de validade e precisão. Na pesquisa social, a observação pode ser: 1. simples, quando o pesquisador é espectador e observa os fatos; 2 . sistemática, quando é utilizada em pesquisa que tem como objeto a descrição precisa dos fenômenos.

Seguindo roteiro prescrito de elementos a serem analisados, os pontos considerados problemáticos tiveram registros fotográficos e também na forma escrita, avaliados de acordo com o cumprimento da legislação em vigor, com base na NBR 9050/2004, na Cartilha de Bolso: Acessibilidade do Conselho Nacional do Ministério Público e no Guia de Acessibilidade do Governo do Estado do Ceará (2009).

\subsection{Termos e Definições}

Inicialmente, consideramos importante o entendimento dos conceitos que acercam o tema, para isso, apresentamos as definições constantes no Decreto nำ5.296/2004 e na Norma da ABNT, NBR 9050/2004.

\section{- Acessibilidade}

Define-se acessibilidade como a possibilidade e condição de alcance, percepção e entendimento para a utilização com segurança e autonomia, total ou assistida, dos espaços, mobiliários e equipamentos urbanos, das edificações, dos serviços de transporte e dos dispositivos, sistemas e meios de comunicação e informação, por pessoa portadora de deficiência ou com mobilidade reduzida. (NBR 9050/2004).

\section{- Acessível}

Espaço, edificação, mobiliário, equipamento urbano ou elemento que possa ser alcançado, acionado, utilizado e vivenciado por qualquer pessoa, inclusive aquelas com mobilidade

\footnotetext{
${ }^{1}$ Método de análise que possibilita a identificação de aspectos positivos e negativos do edifício, consistindo em percorrer todo o edifício, preferencialmente munido de plantas ou acompanhado do projetista ou de usuários, de modo que se possa formular perguntas com o objetivo de conhecer melhor o edifício, sua construção e as atuais funções de cada ambiente, como é utilizado por seus usuários. Ver mais sobre o assunto em Preiser (1988).
} 


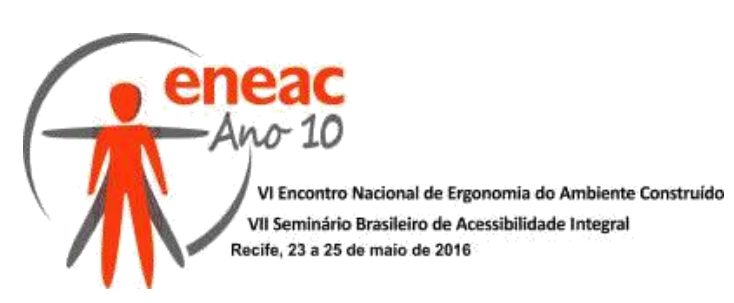

reduzida. O termo acessível implica tanto acessibilidade física como de comunicação. (NBR 9050/2004).

\section{- Adaptável}

Espaço, edificação, mobiliário, equipamento urbano ou elemento cujas características possam ser alteradas para que se torne acessível. (NBR 9050/2004).

\section{- Barreira Arquitetônica, Urbanística ou Ambiental}

Qualquer elemento natural, instalado ou edificado que impeça a aproximação, transferência ou circulação no espaço, mobiliário ou equipamento urbano. (NBR 9050/2004).

\section{- Deficiência}

Define-se como deficiência, a redução, limitação ou inexistência das condições de percepção das características do ambiente ou de mobilidade e de utilização de edificações, espaço, mobiliário, equipamento urbano e elementos, em caráter temporário ou permanente. As deficiências podem ser classificadas como:

a. Deficiência física, na qual há alteração completa ou parcial de um ou mais segmentos do corpo humano, acarretando o comprometimento da função física;

b. Deficiência auditiva, na qual há perda bilateral, parcial ou total, de 41 decibéis ( $\mathrm{dB}$ ) ou mais;

c. Deficiência visual, podendo ser cegueira, na qual a acuidade visual é igual ou menor que 0,05 no melhor olho, baixa visão, na qual a acuidade visual está entre 0,3 e 0,05 no melhor olho, casos no quais a somatória da medida do campo visual em ambos os olhos for igual ou menos que $60^{\circ}$, ou a ocorrência simultânea de quaisquer das condições anteriores;

d. Deficiência mental, na qual o funcionamento intelectual significativamente inferior à média , com manifestações antes dos dezoito anos e limitações associadas a duas ou mais áreas de habilidades adaptativas, tais como comunicação, cuidado pessoal, habilidades sociais, utilização dos recursos da comunidade, saúde e segurança, habilidades acadêmicas, lazer, e trabalho;

e. Deficiência múltipla, associação de duas ou mais deficiências.

A pessoa com mobilidade reduzida caracteriza- se como aquela que, não se enquadrando no conceito de pessoa com deficiência, tenha, por qualquer motivo, dificuldade de movimentar-se, permanente ou temporariamente, gerando redução efetiva da mobilidade, flexibilidade, coordenação motora e percepção. Entende-se por pessoa com mobilidade reduzida, a pessoa com deficiência, idosa, obesa, gestante, entre outros. (Decreto no 5.296/2004)

\section{- Desenho Universal}

O Desenho Universal é definido como aquele que, com a concepção de espaços, artefatos e produtos, visa atender simultaneamente à maior gama de variações possíveis das características antropométricas e sensoriais da população, de forma autônoma, segura e confortável, constituindo -se nos elementos ou soluções que compõem a acessibilidade. (Decreto no 5.296/2004). 


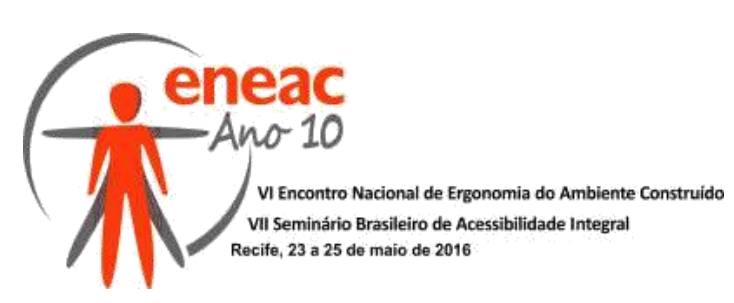

\section{- Espaço acessível}

Espaço que pode ser percebido e utilizado em sua totalidade por todas as pessoas, inclusive aquelas com mobilidade reduzida. (NBR 9050/2004).

\section{- Edificações de Uso Público}

O uso público pode ser classificado como aquele disponibilizado para o público em geral e pode ocorrer em edificações ou equipamentos de propriedade pública ou privada. As edificações de uso público são aquelas administradas por entidades da administração pública, direta ou indireta, ou por empresas prestadoras de serviços públicos e destinadas ao público em geral. (Decreto nำ5.296/2004)

\section{- Equipamento Urbano}

Todos os bens públicos e privados, de utilidade pública, destinados à prestação de serviços necessários ao funcionamento da cidade, implantados mediante autorização do poder público, em espaços públicos e privados. (NBR 9050/2004).

\section{- Impraticabilidade}

Condição ou conjunto de condições físicas ou legais que possam impedir a adaptação de edificações, mobiliário, equipamentos ou elementos à acessibilidade. (NBR 9050/2004).

\section{ESTUDO DE CASO}

A Biblioteca Pública Governador Menezes Pimentel foi criada em 25 de Março de 1867, como a Biblioteca Provincial do Ceará, com um acervo de 1700 livros e com função de Arquivo Público, sendo, portanto, o equipamento cultural mais antigo do Estado do Ceará. Em 6 de Fevereiro de 1975, o então presidente Ernesto Geisel, inaugurou o atual prédio da biblioteca, portanto precedendo às legislações que estabeleceram as normas de acessibilidade e desenho universal. Está localizada dentro do quadrilátero formado pela Rua Bóris, a oeste; a Rua José Avelino, ao norte; a Rua Almirante Jaceguai, ao leste; e a Avenida Presidente Castelo Branco, ao sul (Figura 1). Forma o complexo cultural situado entre o centro da cidade e a praia de Iracema, ao lado do Centro Cultural Dragão do Mar, Teatro São José e Praça do Cristo Redentor. Marca presença também neste complexo, o Seminário da Prainha.

Em 22 de maio de 1978, pelo decreto no 12.768, o governador Waldermar Alcântara alterou o nome da Biblioteca Pública do Estado para a nomenclatura atual, Biblioteca Pública Governador Menezes Pimentel. A biblioteca é mantida pelo Governo do Estado do Ceará, por meio da Secretaria de Cultura do Estado (Secult), e coordena 184 bibliotecas públicas do Estado. Ocupa uma área de $2.272 \mathrm{~m} 2$ distribuídos em cinco pavimentos. Possui um acervo de aproximadamente 115.000 volumes e 300.000 periódicos, em grande parte, informatizado e disponível para seus 10.000 usuários mensais, dentre estes, se encontram tanto pessoas com deficiências sensoriais (audição e visão) como com deficiência física (de locomoção ou coordenação motora).

Em 2002, a biblioteca passou por uma reforma geral contemplando a modernização dos sistemas de sua estrutura e a integração física com o Centro Cultural Dragão do Mar. Em 12 de Março de 2015, a Secult oficializou o início de uma reforma, com investimento de 9 milhões de reais. Em razão desta reforma, inaugurou-se o Espaço Estação, em 23 de Abril 


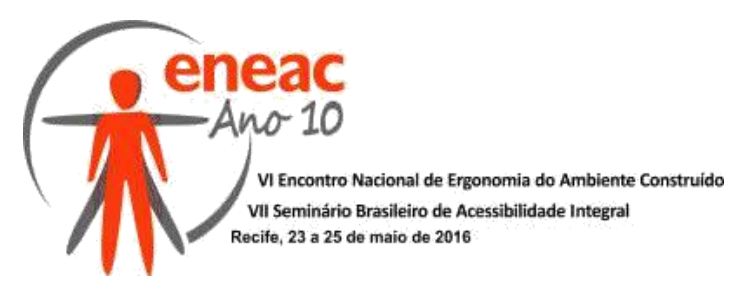

de 2015, onde passou a sediar provisoriamente parte do acervo e das atividades da Biblioteca Pública, que esta fechada integralmente desde fevereiro de 2014.

Figura 1 - Mapa de Localização da Biblioteca Pública Governador Menezes Pimentel

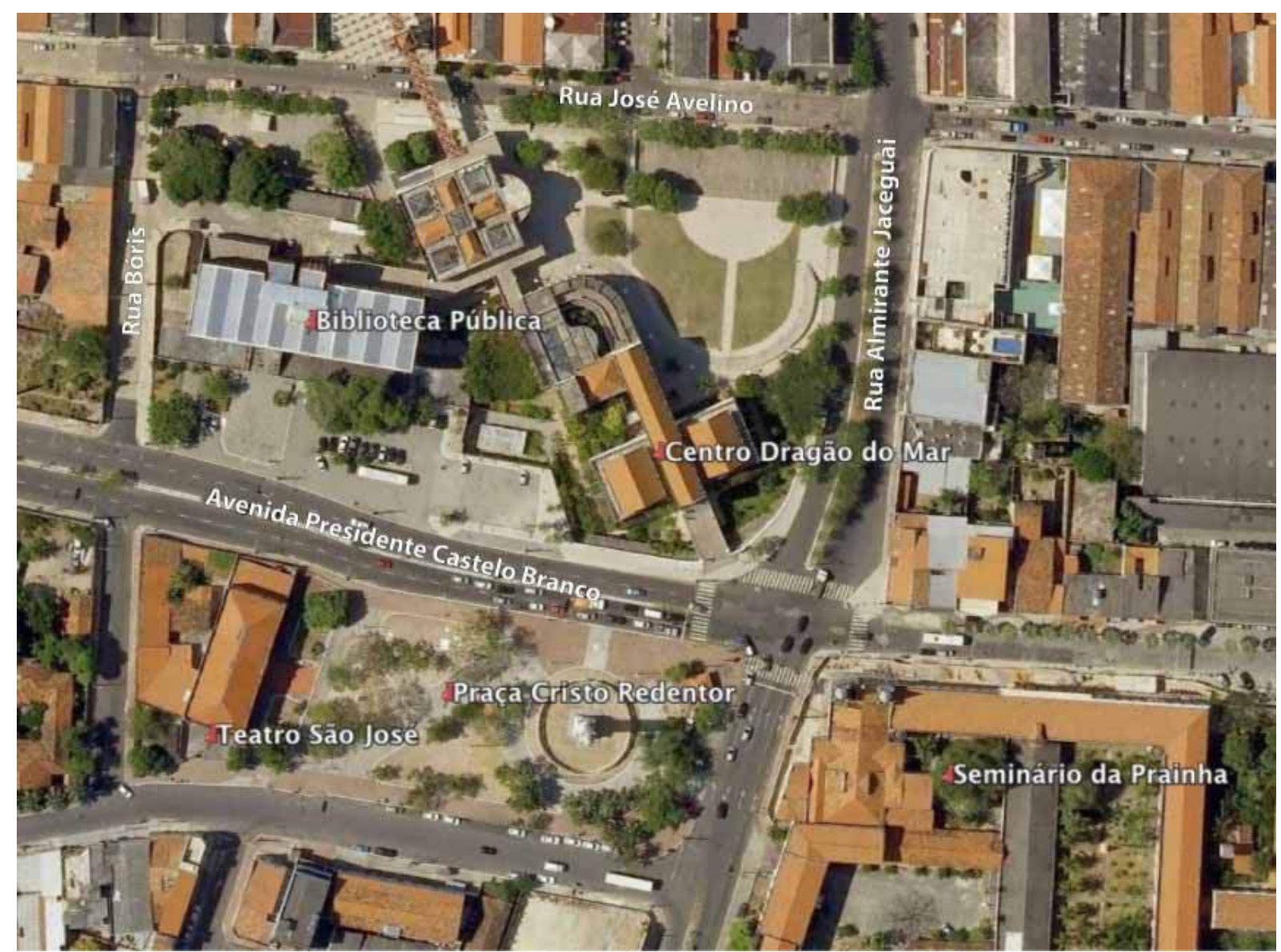

Fonte: Google Earth com anotações elaboradas pela equipe de pesquisa.

\section{1. Resultados}

Para o presente estudo das condições de acessibilidades da Biblioteca Pública Governador Menezes Pimentel foram avaliados os itens conforme o Roteiro Básico para Avaliação de Acessibilidade nas Edificações, do Ministério Público, contido na Cartilha de Bolso: Acessibilidade, elaborada pelo Conselho Nacional do Ministério Público. O Roteiro divide-se em oito itens, sejam eles: calçadas, estacionamentos, acessos, circulações, esquadrias, banheiros, biblioteca e mobiliário. Alguns destes itens dividem-se em subitens com o intuito de melhor expor os quesitos analisados.

Como síntese dos resultados, foi elaborado um quadro geral para apresentar a os itens analisados no estudo de caso. 


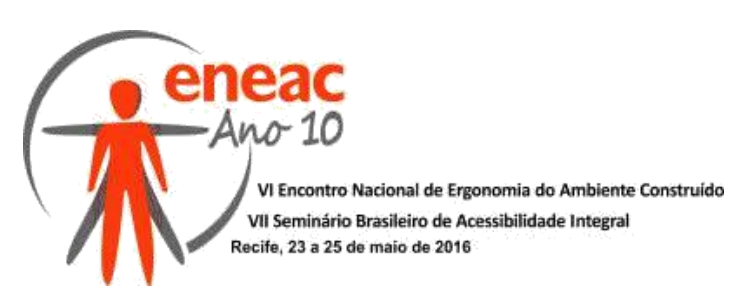

Quadro 1 - Panorama da análise das condições de acessibilidade do local pesquisado

\begin{tabular}{|c|c|c|c|}
\hline $\begin{array}{l}\text { Local ou equipamento } \\
\text { analisado }\end{array}$ & $\begin{array}{c}\text { Referência da } \\
\text { NBR9050/2004 sobre } \\
\text { item analisado }\end{array}$ & $\begin{array}{l}\text { Condição do item } \\
\text { analisado }\end{array}$ & $\begin{array}{l}\text { Resultado: de } \\
\text { acordo ou em } \\
\text { desacordo }\end{array}$ \\
\hline \multirow[t]{6}{*}{ Calçadas } & $\begin{array}{c}\text { Largura mínima }>/= \\
1,20 \mathrm{~m}\end{array}$ & $<1,20 \mathrm{~m}$ & Em desacordo \\
\hline & Rampa $>/=8,33 \%$ & $8,00 \%$ & De acordo \\
\hline & $\begin{array}{c}\text { Piso com superfície } \\
\text { regular, firme, estável e } \\
\text { antiderrapante }\end{array}$ & $\begin{array}{l}\text { Piso com depressões, } \\
\text { ressaltos e material } \\
\text { comprometido }\end{array}$ & Em desacordo \\
\hline & Existência de piso tátil & $\begin{array}{l}\text { Não existe piso tátil } \\
\text { nem balizamento }\end{array}$ & Em desacordo \\
\hline & $\begin{array}{l}\text { Sinalização na saída de } \\
\text { veículos }\end{array}$ & Inexistente & Em desacordo \\
\hline & $\begin{array}{l}\text { Entrada de veículos } \\
\text { respeitando faixa de } \\
\text { pedestre com calçada } \\
\text { nivelada e sem cortes }\end{array}$ & $\begin{array}{c}\text { Calçada apresenta } \\
\text { desnível }\end{array}$ & Em desacordo \\
\hline \multirow[t]{4}{*}{ Estacionamento } & $\begin{array}{c}2 \% \text { das vagas reservadas } \\
\text { a PcD }\end{array}$ & Inexistente & Em desacordo \\
\hline & $\begin{array}{c}5 \% \text { das vagas destinadas } \\
\text { a idosos }\end{array}$ & Inexistente & Em desacordo \\
\hline & $\begin{array}{c}\text { Sinalização adequada } \\
\text { tanto vertical quanto } \\
\text { horizontal }\end{array}$ & $\begin{array}{c}\text { Ausência total de } \\
\text { sinalização adequada } \\
\text { tanto vertical quanto } \\
\text { horizontal. }\end{array}$ & Em desacordo \\
\hline & Rampa junto a vaga & $\begin{array}{c}\text { Existente, porém } \\
\text { numa única vaga sem } \\
\text { sinalização }\end{array}$ & $\begin{array}{l}\text { A existência da } \\
\text { rampa está de } \\
\text { acordo, porém uma } \\
\text { única rampa não } \\
\text { cobre a necessidade } \\
\text { de vagas reservadas }\end{array}$ \\
\hline \multirow[t]{5}{*}{ Acesso à Edificação } & $\begin{array}{c}\text { Tipo de piso regular, } \\
\text { estável e não trepidante }\end{array}$ & $\begin{array}{l}\text { Piso inadequado e } \\
\text { com desgastes, } \\
\text { provoca trepidações }\end{array}$ & Em desacordo \\
\hline & $\begin{array}{c}\text { Tipo de revestimento } \\
\text { antiderrapante }\end{array}$ & Piso liso & Em desacordo \\
\hline & Existência de piso tátil & $\begin{array}{c}\text { Inexiste piso tátil } \\
\text { direcional e de alerta }\end{array}$ & Em desacordo \\
\hline & $\begin{array}{c}\text { Existência de rampa de } \\
\text { acesso principal (público) }\end{array}$ & $\begin{array}{l}\text { Rampa existente, e } \\
\text { embora possua } \\
\text { largura adequada, a } \\
\text { inclinação > 8,33\% }\end{array}$ & Em desacordo \\
\hline & $\begin{array}{c}\text { Existência de rampa } \\
\text { (acesso serviço) }\end{array}$ & Inexistente & Em desacordo \\
\hline \multirow[t]{3}{*}{$\begin{array}{c}\text { Circulação Interna - } \\
\text { Horizontal }\end{array}$} & $\begin{array}{l}\text { Circulação de uso público } \\
\min =1,50 \mathrm{~m}\end{array}$ & $\begin{array}{c}\text { Varia entre os } \\
\text { pavimentos, sendo a } \\
\text { mínima de } 1,65 \mathrm{~m}\end{array}$ & De acordo \\
\hline & $\begin{array}{c}\text { Tipo de piso regular, } \\
\text { estável e não trepidante }\end{array}$ & $\begin{array}{l}\text { Piso de cimento } \\
\text { queimado, regular, } \\
\text { estável e não } \\
\text { trepidante, }\end{array}$ & De acordo \\
\hline & Existência de piso tátil & $\begin{array}{l}\text { Não possui piso tátil } \\
\text { de alerta ou direcional }\end{array}$ & Em desacordo \\
\hline
\end{tabular}




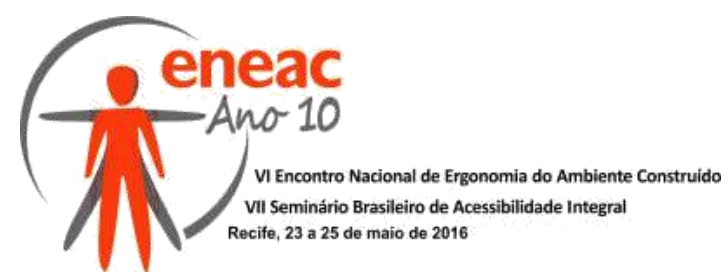

\begin{tabular}{|c|c|c|c|}
\hline \multicolumn{4}{|c|}{ Quadro 1 - Continuação } \\
\hline $\begin{array}{c}\text { Local ou equipamento } \\
\text { analisado }\end{array}$ & $\begin{array}{c}\text { Referência da } \\
\text { NBR9050/2004 sobre } \\
\text { item analisado }\end{array}$ & $\begin{array}{l}\text { Condição do item } \\
\text { analisado }\end{array}$ & $\begin{array}{l}\text { Resultado: de } \\
\text { acordo ou em } \\
\text { desacordo }\end{array}$ \\
\hline \multirow[t]{2}{*}{$\begin{array}{c}\text { Circulação Interna - } \\
\text { Vertical }\end{array}$} & $\begin{array}{l}\text { Escada sinalizada (piso } \\
\text { tátil de alerta antes e } \\
\text { depois, faixa cromo } \\
\text { diferenciada nos degraus } \\
\text { sinalização em anel no } \\
\text { corrimão, }\end{array}$ & $\begin{array}{l}\text { Escada não } \\
\text { sinalizada }\end{array}$ & Em desacordo * \\
\hline & $\begin{array}{c}\text { Existência de elevador } \\
\text { (corrimão, sinalização } \\
\text { com piso tátil de alerta, } \\
\text { sinalização interna) }\end{array}$ & $\begin{array}{l}\text { Não possui corrimão, } \\
\text { nem piso tátil de } \\
\text { alerta, nem } \\
\text { sinalização interna* } \\
\end{array}$ & Em desacordo \\
\hline \multirow[t]{4}{*}{$\begin{array}{c}\text { Setores destinados aos } \\
\text { usuários }\end{array}$} & $\begin{array}{l}\text { Tipo de piso regular, } \\
\text { estável e não trepidante }\end{array}$ & $\begin{array}{l}\text { Piso em borracha } \\
\text { pastilhada por toda } \\
\text { sua extensão, } \\
\text { inclusive no setor de } \\
\text { Braille, o que pode } \\
\text { acarretar numa } \\
\text { confusão com relação } \\
\text { ao piso tátil de alerta. }\end{array}$ & Em desacordo \\
\hline & $\begin{array}{c}\text { Espaço de leitura, mesas } \\
\text { de estudo e terminais de } \\
\text { consulta com } \\
\text { espaçamento para } \\
\text { aproximação frontal de } \\
0,80 \times 1,20 \mathrm{~m} \text {, e sob a } \\
\text { mesa de } 0,50 \mathrm{~m} \text {; e altura } \\
\text { entre } 0,75 \mathrm{~m} \mathrm{e} 0,85 \mathrm{~m}\end{array}$ & $\begin{array}{l}\text { Espaçamento para } \\
\text { aproximação frontal e } \\
\text { sob a mesa } \\
\text { adequados; possui } \\
\text { alturas reguláveis } \\
\text { dentro do limite } \\
\text { permitido }\end{array}$ & De acordo \\
\hline & $\begin{array}{l}\text { Balcões de atendimento } \\
\text { com altura máxima de } \\
0,90 \mathrm{~m} \text { e permitindo } \\
\text { avanço sob de } 0,30 \mathrm{~m}\end{array}$ & $\begin{array}{l}\text { Balcões com alturas } \\
\text { diversas, sendo a } \\
\text { mínima de } 1,00 \mathrm{~m}\end{array}$ & Em desacordo \\
\hline & $\begin{array}{c}\text { Estantes com } \\
\text { espaçamento mínimo de } \\
0,90 \text { entre elas, e altura } \\
\text { no intervalo de } 0,40 \mathrm{~m} \text { e } \\
1,20 \mathrm{~m}\end{array}$ & $\begin{array}{c}\text { Espaçamento mínimo } \\
\text { adequado, mas altura } \\
\text { fora do intervalo, com } \\
\text { prateleiras mais altas } \\
\text { e mais baixas que o } \\
\text { indicado } \\
\end{array}$ & Em desacordo \\
\hline \multirow[t]{2}{*}{ Mobiliário } & $\begin{array}{l}\text { Telefone público - } 1 \text { por } \\
\text { pavimento, com } 5 \% \\
\text { adaptados, ou no mínimo } \\
1 \text { acessível com altura } \\
\text { máxima de } 1,20 \mathrm{~m} \text {, com } \\
\text { piso de alerta }\end{array}$ & $\begin{array}{l}\text { Apenas } 1 \text { existente, } \\
\text { não adaptado, com } \\
\text { altura de } 1,30 \mathrm{~m} \mathrm{e} \\
\text { sem piso de alerta }\end{array}$ & Em desacordo \\
\hline & $\begin{array}{l}\text { Bebedouro - } 50 \% \\
\text { acessíveis, ou no mínimo } \\
1 \text {, permitindo } \\
\text { aproximação frontal sob } \\
\text { equipamento, com altura } \\
\text { máxima de } 0,90 \mathrm{~m}\end{array}$ & $\begin{array}{l}\text { Há espaço reservado } \\
\text { para bebedouro, mas } \\
\text { não há equipamento } \\
\text { instalado; Espaço } \\
\text { reservado não } \\
\text { permite aproximação } \\
\text { frontal }\end{array}$ & Em desacordo \\
\hline
\end{tabular}




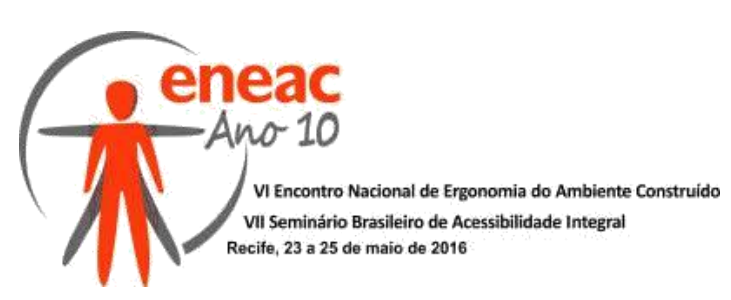

\begin{tabular}{|c|c|c|c|}
\hline \multicolumn{4}{|c|}{ Quadro 1 - Continuação } \\
\hline $\begin{array}{l}\text { Local ou equipamento } \\
\text { analisado }\end{array}$ & $\begin{array}{c}\text { Referência da } \\
\text { NBR9050/2004 sobre } \\
\text { item analisado }\end{array}$ & $\begin{array}{l}\text { Condição do item } \\
\text { analisado }\end{array}$ & $\begin{array}{l}\text { Resultado: de } \\
\text { acordo ou em } \\
\text { desacordo }\end{array}$ \\
\hline \multirow[t]{2}{*}{ Mobiliário } & $\begin{array}{l}\text { Assentos fixos - com } \\
\text { área destinada do } \\
\text { Módulo de Referência ao } \\
\text { lado do banco, com } \\
\text { sinalização internacional } \\
\text { de acesso }\end{array}$ & $\begin{array}{l}\text { Existe área ao lado } \\
\text { dos bancos, no } \\
\text { entanto esta não é } \\
\text { sinalizada }\end{array}$ & Em desacordo \\
\hline & $\begin{array}{c}\text { Plano e Mapas Táteis - } \\
\text { instalados em superfície } \\
\text { com altura entre } 0,90 \mathrm{~m} \text { e } \\
1,10 \mathrm{~m} \text {, possuindo } \\
\text { reentrância com, no } \\
\text { mínimo, } 0,30 \text { de altura e } \\
0,30 \text { de profundidade } \\
\text { para aproximação frontal } \\
\text { de PCR }\end{array}$ & Inexistente & Em desacordo \\
\hline \multirow[t]{2}{*}{ Esquadrias } & $\begin{array}{c}\text { Portas - largura mínima } \\
\text { de } 0,80 \mathrm{~m} \text { e altura de } \\
2,10 \mathrm{~m} ; \text { com maçanetas } \\
\text { tipo alavanca, estas com } \\
\text { altura entre } 0,90 \mathrm{~m} \text { e } \\
1,10 \mathrm{~m} \text {; com sinalização } \\
\text { visual no centro da porta } \\
(1,40 \mathrm{~m}-1,60 \mathrm{~m}) \text { e tátil em } \\
\text { relevo }(0,90 \mathrm{~m}-1,10 \mathrm{~m}) \text { no } \\
\text { lado externo } \\
\end{array}$ & $\begin{array}{l}\text { Possuem larguras e } \\
\text { alturas adequadas, no } \\
\text { entanto as maçanetas } \\
\text { não são do tipo } \\
\text { alavanca }{ }^{* * *} \text {; há } \\
\text { sinalização visual mas } \\
\text { não sinalização tátil }\end{array}$ & Em desacordo \\
\hline & $\begin{array}{c}\text { Janelas - altura de } \\
\text { comandos a } 1,20 \mathrm{~m}, \mathrm{e} \\
\text { altura de alcance visual a } \\
1,15 \mathrm{~m}\end{array}$ & $\begin{array}{l}\text { Basculantes, com } \\
\text { comando de alavanca } \\
\text { e peitoril de } 0,90 \mathrm{~m}\end{array}$ & De acordo \\
\hline Banheiros & $\begin{array}{l}\text { Unidade acessível, para } \\
\text { cada sexo, em todos os } \\
\text { pavimentos, ou pelo } \\
\text { menos uma acessível, } \\
\text { unissex, com entrada } \\
\text { independente dos } \\
\text { sanitários coletivos; com } \\
\text { dimensão mínima de } \\
1,50 \mathrm{~m} \times 1,70 \mathrm{~m} \text {; com } \\
\text { barras de apoio } \\
\end{array}$ & $\begin{array}{l}\text { Somente um andar } \\
\text { com unidade } \\
\text { acessível e com } \\
\text { barras de apoio, no } \\
\text { entanto, esta ainda } \\
\text { não está dentro da } \\
\text { norma por ter } \\
\text { dimensões de } 1,30 \mathrm{~m} \\
\times 1,30 \mathrm{~m}\end{array}$ & Em desacordo \\
\hline Vestiários & $\begin{array}{c}\text { Chuveiro - com rampa } \\
\text { para eliminar desnível do } \\
\text { box; com banco } \\
\text { articulado; com barra de } \\
\text { apoio; permitir área de } \\
\text { transferência }(0,80 \mathrm{~m} x \\
1,20 \mathrm{~m}) \text {; com ducha } \\
\text { manual e registro tipo } \\
\text { alavanca. }\end{array}$ & $\begin{array}{l}\text { Possui desnível de } 4 \\
\text { cm, sem rampa; não } \\
\text { possui banco } \\
\text { articulado ou barra de } \\
\text { apoio; não há espaço } \\
\text { para área de } \\
\text { transferência }\end{array}$ & Em desacordo \\
\hline
\end{tabular}




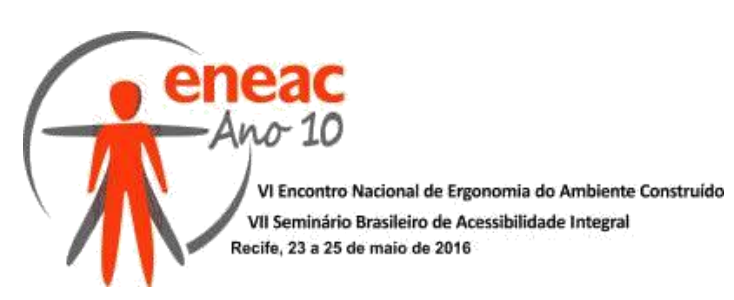

\section{Quadro 1 - Continuação}

Observações:

\footnotetext{
* A escada principal apresenta irregularidades, altura do espelho é desigual, sendo o primeiro de $0,13 \mathrm{~m}$ e os demais de $0,15 \mathrm{~m}$, não atendendo as dimensões adequadas, que devem ser entre $0,16 \mathrm{~m}$ e $0,18 \mathrm{~m}$. O piso dos degraus é de mármore e estável, no entanto não possui o piso tátil de alerta ou faixa de sinalização junto às bordas.

** Informação obtida através de consulta a funcionários devido a interdição do elevador no momento da coleta de dados.

*** Portas de setores destinados a acervo de vidro com puxador tipo redondo; e de serviço e demais setores, como banheiros e vestiários, de madeira com maçaneta tipo bola.
}

Fonte: Elaborado pela Equipe de Pesquisa

\section{CONSIDERAÇÕES FINAIS}

A arquitetura da Biblioteca Pública analisada, como a de muitos dos prédios públicos mais antigos, ou que foram construídos antes da NBR 9050 (1985/1994/2004) apresenta uma série de obstáculos quanto às questões de acessibilidade. Na verdade, foi somente com o Decreto Federal ํ․ 5.296/2004, que as ações no sentido de propiciar acessibilidade espacial se tornaram mais efetivas, tendo no Ministério Público um aliado na cobrança do cumprimento da lei.

A construção da biblioteca precede às legislações que estabeleceram as normas de acessibilidade e desenho universal, entretanto reformas recentes falharam em adaptar 0 espaço aos princípios de diversidade humana, e assim permanece excludente um espaço que deveria pertencer a toda população. O problema é agravado pelo fato de que mais uma reforma está sendo realizada e ainda se encontram problemas de acessibilidade.

Apesar de já ter sido objeto de reforma arquitetônica, por mais de uma vez desde a implementação das legislações, as reformas realizadas na Biblioteca Pública do Estado do Ceará deixaram ainda inadequações relativas ao atendimento aos princípios de diversidade humana, acessibilidade e usabilidade, embora haja evidências de terem ocorrido preocupações com possíveis usuários com deficiência.

Ainda se apresentam problemas tais como: ausência de sinalização, inclinação inadequada de rampas, banheiros sem unidades acessíveis, mobiliários inadequados, a ausência de vagas especiais, entre outros problemas, dificultam o acesso de pessoas com deficiência ao edifício.

Há uma rampa de acesso localizada junto de uma das vagas de estacionamento, vencendo o desnível da calçada, assim, em conjunto com a rampa do acesso principal da edificação, tem o potencial de constituir uma rota acessível entre estacionamento e Biblioteca. Contudo, a falta de sinalização não garante o direito de pessoas com deficiência ou mobilidade reduzida de utilizar esta vaga.

Para garantir o acesso universal à biblioteca se fazem necessárias intervenções nos dois estacionamentos existentes. Estas intervenções devem incluir: a demarcação de vagas destinadas a pessoas com deficiência e vagas destinadas a idosos por meio de sinalização vertical e horizontal, respeitando as dimensões necessárias para a livre circulação entre a vaga e a rota acessível. A intervenção deve ainda englobar a instalação de novas rampas de acesso, uma vez que a única rampa existente não é suficiente para todas as vagas reservadas necessárias. 


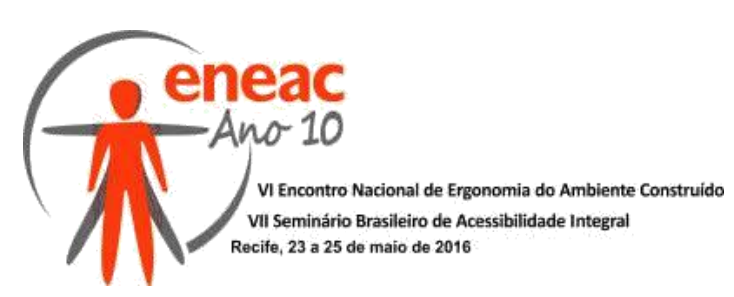

Enfim, após a análise, fica evidente que ainda existem inadequações na edificação quanto a acessibilidade espacial, o que reduz a possibilidade de receber todo o público, respeitando as diferentes necessidades de cada pessoa, porém com algumas intervenções simples seria possível criar pelo menos uma rota acessível que desse acesso a todos os espaços da biblioteca. Instalações de rampas e correções na existente, bem como remoção de algumas barreiras físicas existentes, contribuiriam para isso. Faz-se necessário também a correção das imperfeições nos pisos, em alguns locais é preciso substituir por completo o piso, optando por materiais antiderrapantes. Também se faz necessária a instalação de sinalização adequada, como mapas táteis e avisos em Braille, além da implantação de pisos táteis direcional e de alerta.

É necessária uma intervenção com o foco na acessibilidade, somente assim será possível garantir a inserção de pessoas com deficiência e mobilidade reduzida no espaço da biblioteca, sem discriminar, nem causar constrangimentos, ou proporcionar riscos. Portanto, garantir o acesso físico a todos é essencial para a inclusão social, e é o único meio de tornar o espaço da Biblioteca Pública do Estado do Ceará realmente democrático.

\section{REFERÊNCIAS BIBLIOGRÁFICAS}

ASSOCIAÇÃO BRASILEIRA DE NORMAS TÉCNICAS. NBR 9050: Acessibilidade a edificações, mobiliário, espaços e equipamentos urbanos. Rio de Janeiro, 2014.

BASTOS, Núbia Maria Garcia. Introdução à metodologia do trabalho acadêmico. 4. ed. Fortaleza: Nacional, 2005.

BRASIL. Decreto 5.296, de 02 de Dezembro de 2004. Brasília, DF, 2004. Disponível em: <http://www.planalto.gov.br/ccivil_03/_ato2004-2006/2004/decreto/d5296.htm>. Acesso em: 24 de Junho de 2015.

BRASIL. Lei 10.098, de 19 de Dezembro de 2000 . Brasília, DF, 2000. Disponível em: <http://www.planalto.gov.br/ccivil_03/leis/110098.htm>. Acesso em: 24 de Junho de 2015.

CONSELHO NACIONAL DO MINISTÉRIO PÚBLICO. Todos juntos por um Brasil mais acessível. Cartilha de Bolso: Acessibilidade. Conselho Nacional do Ministério Público. 3aㅗ Impressão. Brasília: CNMP, 2014.

CEARÁ. Guia de Acessibilidade: espaços públicos e edificações. Elaboração: Nadja G.S. Dutra Montenegro; Zilsa Maria Pinto Santiago; Valdemice Costa de Sousa. Fortaleza: SEINFRA-CE, 2009.

EMMANUELLI, Mara Neide. Acessibilidade física em bibliotecas universitárias: um direito de todos. Porto Alegre, UFRGS, 2009. 82p. Monografia de Conclusão de Curso (Especialização em Gestão de Bibliotecas Universitárias). Faculdade de Biblioteconomia e Comunicação, Universidade Federal do Rio Grande do Sul, 2009. Disponível em: <http://www.lume.ufrgs.br/handle/10183/18490>. Acesso em: 24 de Junho de 2015.

FONSECA, C. C. R.; GOMES, G. F.; VANZ, S. A. de S. Acessibilidade e Inclusão em Bibliotecas: Um Estudo de Caso. In: SEMINÁRIO NACIONAL DE BIBLIOTECAS UNIVERSITÁRIAS - SNBU 17., 2012, Porto Alegre: Universidade Federal do Rio Grande do Sul, $2012 . \quad$ Disponível em: <https://www.lume.ufrgs.br/bitstream/handle/10183/61049/000864667.pdf? sequence=1>. Acesso em: 24 de Junho de 2015.

GIL, Antônio C. Técnicas de pesquisa em economia e elaboração de monografias. 3 ed. São Paulo: Atlas, 2000. 


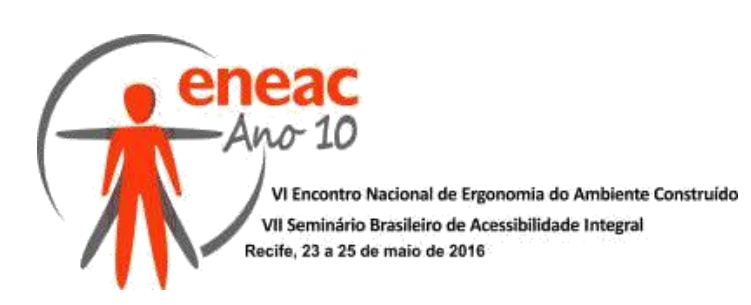

GOOGLE. Google Earth. Versão 7.1.5.1557. Ano 2016. Fortaleza/CE. Disponível em: <>. Acesso em: 24 de Junho de 2015.

INSTITUTO BRASILEIRO DE GEOGRAFIA E ESTATíSTICA. Censo Demográfico 2010: Características Gerais da População, Religião e Pessoas com Deficiência. Rio de Janeiro, 2010.

Disponível em: <http://biblioteca.ibge.gov.br/visualizacao/periodicos/94/cd_2010_religiao_deficiencia.pdf >. Acesso em: 24 de Junho de 2015.

NICOLETTI, Tamini Farias. Checklist para bibliotecas: um instrumento de acessibilidade para todos. Porto Alegre, UFRGS, 2010. 98p. Monografia de Conclusão de Curso (Curso de Biblioteconomia) . Faculdade de Biblioteconomia e Comunicação, Universidade Federal do Rio Grande do Sul, 2010. Disponível em: <www.lume.ufrgs.br/handle/10183/28114>. Acesso em: 24 de Junho de 2015.

PREISER, Wolfgang F.E. Post-occupancy evaluation. New York: Van Nostrand Reinhold, 1988.

SANTIAGO, Z. M. P.; COSTA, A. P. B. G.; LEITÃO, M. de A. Avaliação de Condições de Acessibilidade em Projetos de Adaptação de Edificações Públicas em Fortaleza. In:

ENCONTRO NACIONAL DE ERGONOMIA DO AMBIENTE CONSTRUÍDO: V SEMINÁRIO BRASILEIRO DE ACESSIBILIDADE INTEGRAL, 4., 2013, Florianópolis: Universidade Federal de Santa Catarina, 2013.

SANTIAGO, Z. M. P.; SANTIAGO, C. Q. de; SOARES, T. S. Acessibilidade no Espaço Público: o caso das praças de Fortaleza. In: CONGRESSO INTERNACIONAL DE ERGONOMIA E USABILIDADE DE INTERFACES HUMANO-TECNOLOGIA-PRODUTO, INFORMAÇÕES, AMBIENTES CONSTRUÍDOS E TRANSPORTE, 15., 2015, Recife: Universidade Federal de Pernambuco, 2015. Disponível em: <http://pdf.blucher.com.br/designproceedings/15ergodesign/48-E054.pdf>. Acesso em: 24 de Junho de 2015.

Metas do Plano Nacional de Cultura. Disponível em: <http://pnc.culturadigital.br/metas/page/3/>. Acesso em: 20 de Junho de 2015. 